CASE REPORT

\title{
latrogenic injury to the breast bud causing breast hypoplasia
}

\author{
A Goyal, R E Mansel
}

Postgrad Med J 2003;79:235-236

A 14 year old girl with iatrogenic breast asymmetry is reported. She had multiple operations to the left anterior chest wall in the neonatal period for diaphragmatic hernia that resulted in multiple scars, which damaged the left breast bud. A better thoracotomy incision avoiding the breast bud could prevent later breast hypoplasia.

S ome variation in breast size is normal and is common in most women. When this asymmetry becomes large it may disrupt the patient's life. Injury to the breast bud as a result of chest wall trauma especially in female gymnasts during their growth spurt has been reported in the literature as a cause of breast asymmetry. ${ }^{1}$ Accidental excision of the breast bud with a lump is known to cause hypoplasia. We report an interesting case where breast hypoplasia was caused by surgical injury to the breast bud or its vascular supply because of a thoracotomy incision.

\section{CASE REPORT}

A 14 year old girl presented to the clinic with asymmetric breast development. At birth she was diagnosed to have a left diaphragmatic hernia with a gastric perforation. She underwent repair of a left diaphragmatic hernia and closure of the gastric perforation through a left upper abdomen transverse incision. Unfortunately, nine days postoperatively, she developed a recurrence of the left diaphragmatic hernia with gastric perforation. She was taken to theatre for a laparotomy and left thoracotomy. The left upper transverse incision was reopened and a left thoracotomy incision was made dividing the nipple areola complex. Two chest drains were placed after the completion of the repair. The patient was discharged after a hospital stay of two months. After discharge she developed a persistent sinus discharging pus in the left lateral side of the chest at the site of the thoracic drain. The sinus was found to be communicating with a large cavity just superior to the left hemidiaphragm. This was treated by exploration of the sinus along with resection of a small section of the rib in relation to the sinus. The cavity was opened and drained.

On examination when she presented at age 14 her right breast was normally developed. Her left breast was smaller (fig 1). The left breast mound was growing symmetrically with the thoracotomy scar over the top of it. There was one deep scar at the site of the previous thoracic sinus in the lateral part of the inframammary fold and this in fact was tethering the skin and distorting the breast somewhat. The main breast scar was not thought to be inhibiting the breast growth and it was more likely that she had asymmetric breast development. In any case, no surgical intervention was felt necessary until she was older to see the final rate of growth of the left breast.

She was reviewed again one year later, when it was noticed that she had not had much breast growth on the left side. It was decided that she required some augmentation of the left
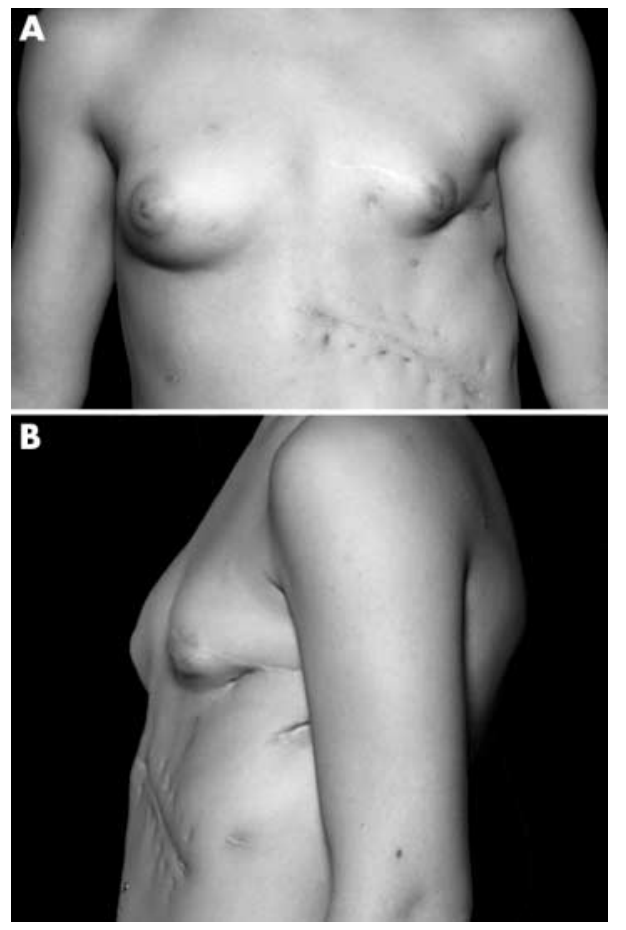

Figure 1 Preoperative breasts with noticeable asymmetry: (A) anterior view and (B) lateral view (published with patient's permission).

side for psychological reasons. She underwent left breast augmentation at the age of 16 years. A tissue expander (Becker $200 \mathrm{ml}$ ) was inserted in the retromammary space; $70 \mathrm{ml}$ of saline was added to the implant at operation. Retromammary dissection was difficult due to the old scars and retromammary adhesions. The thoracotomy scar through the middle of the breast seemed to be fairly flexible and expanded reasonably. The inferior scar at the lateral part of the inframammary fold was found to be tethering the breast down and was thus excised and the adjoining skin freed. Good postoperative symmetry was obtained (fig 2). She is pleased with the outcome and has resumed a normal lifestyle.

\section{DISCUSSION}

At puberty, under the influence of ovarian hormones, the breast bud grows rapidly. The epithelial sprouts of the mammary gland branch further and become separated by increasing deposition of fat. Any injury to the breast bud or its vascular supply would impair its growth resulting in breast hypoplasia. Significant asymmetry could affect the patient adversely causing psychological problems including decreased self confidence and self esteem. Fortunately, treatment usually leads to a complete resolution of any psychological problems associated with the asymmetry. ${ }^{2}$ Chest wall trauma especially 


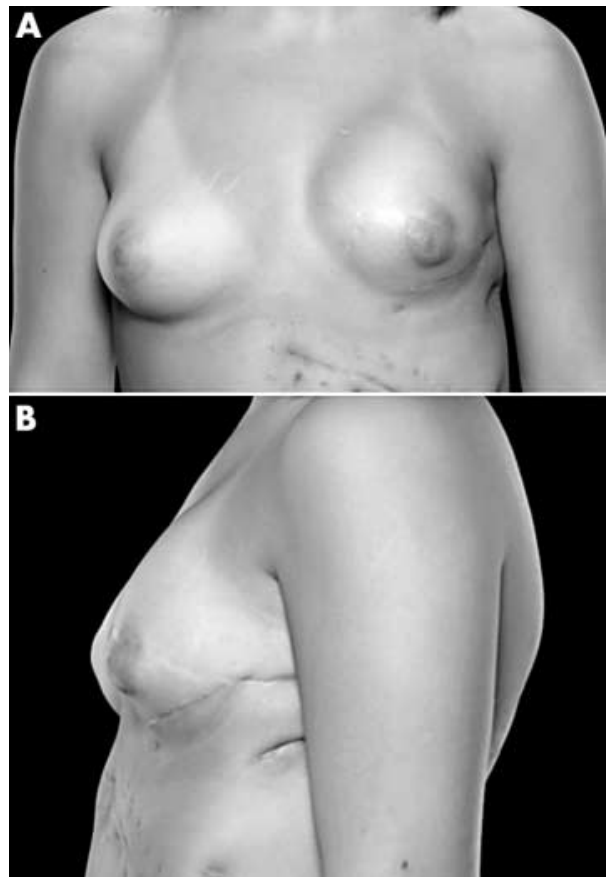

Figure 2 Postoperative breasts displaying good symmetry: (A) anterior view and (B) lateral view (published with patient's permission).

in female gymnasts during the growth spurt has been recognised as a cause of breast asymmetry. However, thoracotomy incision has never been reported as a cause for breast asymmetry in the literature.

The recognition of this problem is important as it can be prevented if the surgeon is aware of it. In the above case it is

\section{Learning points}

- Breast asymmetry can have serious psychological consequences for young girls.

- Thoracotomy incision causing injury to the breast bud or its vascular supply can lead to breast hypoplasia.

- Surgical incision should avoid injury to the breast bud when possible.

likely that the thoracotomy incision through the breast bud may have resulted in direct damage to it. The extensive scarring near the breast bud because of the chest drains and the recurrent sinus also caused tethering of the skin of the lower breast resulting in distortion.

When the patient has to undergo surgical procedures as a life saving measure cosmesis cannot be a priority. However breast asymmetry can be prevented by avoiding placement of surgical incisions through the breast bud or in close proximity to it, without comprising the primary aim of the procedure.

\section{Authors' affiliations}

A Goyal, R E Mansel, Department of Surgery, University of Wales College of Medicine, Cardiff

Correspondence to: Mr Amit Goyal, Department of Surgery, University of Wales College of Medicine, Heath Park, Cardiff CF14 4XN, UK; goyala@cf.ac.uk

Submitted 6 December 2002

Accepted 3 January 2003

\section{REFERENCES}

1 Jansen DA, Spencer Stoetzel R, Leveque JE. Premenarchal athletic injury to the breast bud as the cause for asymmetry: prevention and treatment. Breast J 2002;8:108-1 11.

2 Simon BE, Hoffman S, Kahn S. Treatment of asymmetry of the breasts. Clin Plast Surg 1975;2:375.

\section{POSTGRADUATE MEDICAL JOURNAL}

Web editor

W

are looking for a web editor to join the editorial team of the Postgraduate Medical Journal. Workng closely with the team based in Leicester and the web master for BMJ journals at BMA House, the web editor will be instrumental in developing the electronic version of the journal, PMJ

Online (www.postgradmedj.com).

The Postgraduate Medical Journal is a well established, international journal committed to continuing professional development. The editorial team is keen to harness the potential offered by electronic publication and needs a web editor to make the difference between thinking and doing.

You will be medically qualified and have an enthusiastic commitment to electronic publishing. You will be familiar with web based journals and, through your knowledge of the type of information clinicians need for their day-to-day practice, help shape the journal's website to achieve maximum impact for readers and authors. You will have excellent interpersonal and communication skills to influence and convince others, and the tenacity to turn ideas into practice.

An annual honorarium of $£ 3000$ is payable, but the remuneration will be less important to you than the opportunity to gain editorial and publishing experience within the BMJ Publishing Group. We would be pleased to provide applicants with temporary free access to the online journal to facilitate their application.

To apply, please send a brief CV and a covering letter to the editor: Postgraduate Medical Journal, Leicester General Hospital NHS Trust, Gwendolen Road, Leicester LE5 4PW, UK (email: pmj@btinternet.com).

For an informal discussion about the post, please call the editorial office: tel: +44 (0)116273 0221 (fax: $+44(0) 1162730820)$

Closing date 15 May 2003 